\title{
EAP Need Analysis of Undergraduates in Agricultural Universities in the Border Provinces of China
}

\author{
Xuyan $\mathrm{Xu}^{1}$, Luanhua Chang ${ }^{1 *}$, Hui Zhang ${ }^{2}$ \\ ${ }^{1}$ Foreign Language School, Yunnan Agricultural University, Kunming, China. \\ ${ }^{2}$ College of Agronomy and biotechnology, Yunnan Agricultural University, Kunming, China. \\ *Corresponding author.Email: 343942788@qq.com
}

\begin{abstract}
Under the grand background of the construction of neo-agriculture education, what's the direction of college English reform in agricultural universities in border provinces of China? To answer this question, the author conducted a need analysis of EAP in Yunnan Agricultural University, finding that there are large differences of undergraduates' perception of EAP between in China's top universities and in agricultural universities in border provinces, mainly about the present English level, the learning aims of college English, academic awareness and the academic norms. Despite their weak English foundation, undergraduates in agricultural universities in border provinces subjectively recognize the necessity and importance of EAP. At the end of the article, the author proposes several practical suggestions about the EAP course design in agricultural universities in border provinces.
\end{abstract}

Keywords: EAP, Agricultural University, College English Reform.

\section{INTRODUCTION}

Issued in 2020 by Ministry of Education of PRC, College English Teaching Guide (hereinafter referred to as Guide) points out that college English teaching should focus on language using ability, which especially requires communicative ability of academic English on the basis of enhancing general English using ability, effectively serving undergraduates during their professional exploration. In the Guide, teaching objectives of college English are divided into 3 steps: basic step, improving step and developing step. It is proposed at improving step that students are supposed to write English abstracts and short papers about their major; at developing step, students are supposed to read English literature about their major smoothly, understand the logic and implicit meaning between the lines properly, and form their own opinion after analyzing different perspectives. [1] Academic English is positioned at an unprecedented height in this Guide. The Guide states clearly that the specialties of the university should be taken into consideration during college English reform. In other words, developing objectives of university largely decide the reforming direction of college English. College English reform should facilitate the development of the university and serve the talent cultivation objectives of the university [1]. In the present situation, how should the college English reform in agricultural university be designed? What are students' perception and expectation on academic English? From what perspectives can academic English help students in professional exploration?

Anji Consensus, Beidacang Action, and Beijing Guidelines composed the trilogy of neo-Agriculture Education, which aims at solving the tough and pressing problems hindering educational reform of higher agriculture and forestry education [2]. Under this grand circumstances, agricultural universities in China's border face unprecedented challenges and chances which requires coordinated and balanced development of multidisciplines to break the boundaries of isolated disciplines, integrating such disciplines as humanity, science, engineering and medicine, achieving innovative development of cross-disciplines, finally cultivating highlevel agricultural talents with broad international horizon, critical scientific insights, enormous research potential as well as strict academic attitude.

As one of directions of integrating humanity and agriculture, English for academic purpose (hereinafter refers to EAP) facilitates undergraduates to directly obtain cutting-edge major knowledge in English and to effectively achieve academic communication. Jordan (1997:1) divides EAP into ESAP (English for specific 
academic purpose) and EGAP (English for general academic purpose) [3]. Some scholars (Ma Wulin, 2011, Cai Jigang,2012) explains EGAP as skill-based EAP and ESAP as content-based EAP which is equivalent to the bilingual teaching on one specific major in some Chinese universities [4] [5]. EAP in this paper refers to the EGAP defined above. According to Sinha \& Sadorra (1991:1213), academic English can be understood as a series of methods helping students delve into English literature on their major [6].

EAP teaching contributes to SCI articles written by undergraduates. Quantity and quality of SCI articles which was mainly accomplished by teachers before largely reflect the research level of an agricultural university. However, SCI articles written by students drew public's great attention and aroused heated discussion in academic field. Take Sichuan University as an example, 32 SCI papers were published by undergraduates on Chemistry major as the first or the second author from 2010 to 2013[7]. Undergraduates from less known university can also publish SCI articles. ZhouKou Normal University, an ordinary normal university in Henan Province, is well-known for a SCI article published by 4 undergraduates. It is no doubt that SCI articles written by students not only sharpen the comprehensive strength and competitiveness of the university, but also, to a large extent, reflect the highly emphasis of EAP teaching in these universities. However, Cai Jigang (2019) indicates that EAP is not fully highlighted in the majority of China's universities; he claims that the main contradiction of the foreign language teaching in China lies in the fact that the present college English teaching fails to meet undergraduates' need to study and research their major in English which coincide with the teaching contents of EAP [8].

At present, the need analysis of EAP is mainly conducted in top universities in such developed cities as Beijing and Shanghai. Cai Jigang made an EAP need analysis survey covering Yunnan University ranking first in Yunnan province [8]. However, EAP need analysis of agricultural universities in border provinces is scarcely mentioned. Compared with the comprehensive competitiveness of the top universities in big cities, universities in border provinces are comparatively lagged behind, especially in teachers' level, research ability, students' English level and so on. A large amount of agricultural students from rural areas where the elementary education is comparatively weak even blame English as the barrier inhibiting them from entering into their ideal university. All of the above factors make the obstacles of college English reform, which is an overwhelming trend, especially under the grand background of neo-Agriculture Education.

This paper aims to conduct a need survey of EAP in Yunnan Agricultural University, analyse the undergraduates' expectation and perception of EAP, examine the similarities and differences of EAP need between in agricultural university and in other top universities in developed cities of China, and propose practical suggestions toward the teaching reform of college English in border provinces.

\section{SURVEY}

178 Questionnaires were distributed online to nonEnglish majors including freshmen, sophomores, juniors and seniors in Yunnan Agricultural University which serves as the representative of agricultural universities in border provinces. The majors are divided into 4 categories: humanity, science, engineering and agriculture, which cover all non-English majors in Yunnan Agricultural University. 178 valid questionnaires were collected, in which the proportion of each grade and major category are balanced. In the questionnaire, 20 objective questions (including 12 single-choice questions and 8 multiplechoice questions) were designed to test students' academic norm, and to identify their opinion toward the present college English as well as their perception and expectation toward EAP.

\section{RESULT AND IMPLICATION}

\subsection{Improper Learning Aims of College English}

As for learning aims of college English (see Figure 1), only $35.29 \%$ freshmen view English as a tool to obtain the up-to-date information about their major, while $94.12 \%$ respondents regard CET-4/6 as their primary aim of leaning English in university, which may result from some realistic factors, such as employer's requirements. When being asked the deep reason behind passing CET$4 / 6$ (the scores $\geq 425$ ), most of them are not sure whether the testing content is conducive to their future performance in workforce. This result is largely disaccord with the survey result published by Cai Jigang (2013), who found that $80 \%$ freshmen expect to obtain information and communicate academic findings in English, and more than $60 \%$ freshmen view college English as a tool to help them explore their major (such as search and read professional literatures) [9].

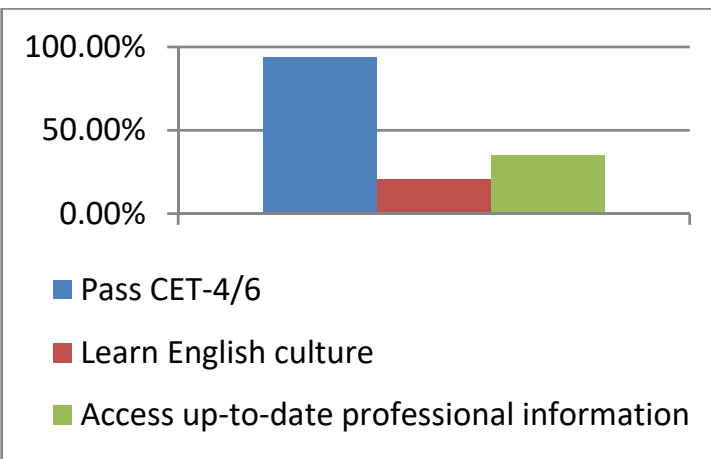

Figure 1 Learning aims of freshmen (multiple-answer question) 
Therefore, there is a large difference of students' learning aims between agricultural university in border provinces and top universities. It is noteworthy that $75 \%$ respondents covering undergraduates of 4 grades in all majors fail to pass CET-4, which further shows the low English level of undergraduates in agricultural universities in border provinces, thus leading to low expectation in EAP.

The survey indicates that students are in desperate need of guidance from teachers in university, due to their misperception of English learning which no longer meets the realistic need of society and discord with the future plan of talent cultivation in neo-agriculture education. According to Cai Jigang, university teachers should serve as the guide to lead students to develop themselves on a higher level, finally meeting the need of students and future society. He stressed that college English reform should not follow students' low-level subjective need, which narrows their horizon and holdback their development to a large extent [5].

\subsection{Irrelevance between Language Level and EAP Need}

In spite of the small proportion of respondents passing CET-4 and students' low confidence of English learning, undergraduates in agricultural universities in border provinces recognized the importance and significance of EAP. Data show that $82 \%$ respondents (including more than $90 \%$ undergraduates majoring in agriculture) think it of great importance to search and read English professional literature, which accords with teaching aim of EAP (see Figure 2).

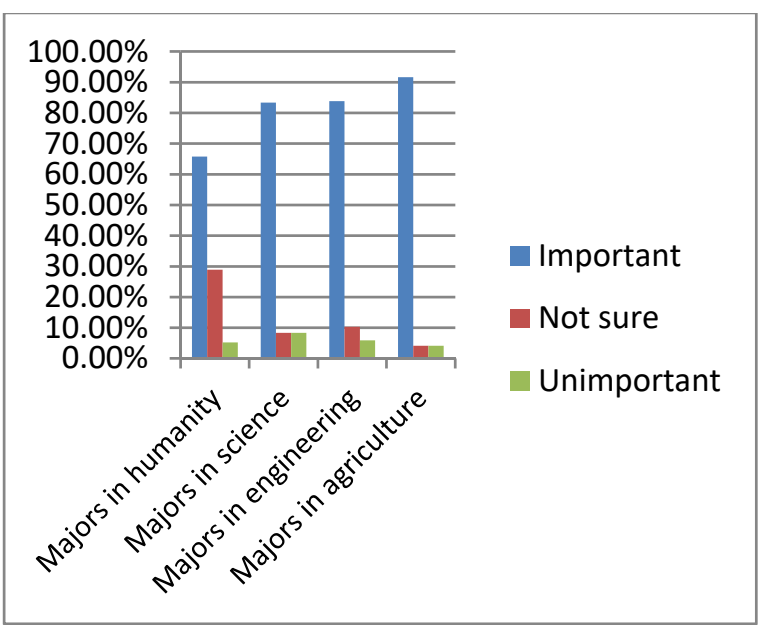

Figure 2 Different majors" answers toward "What do you think of searching and reading English professional literature for your major exploration?'

When being asked the significance of writing papers, the majority of undergraduates agree that writing paper contributes to critical thinking, to comb professional knowledge, to participate in major development and to get access to up-to-date professional information (see
Figure 3). This shows that undergraduates recognize the importance of writing paper which, to a large extent, is affected by such indispensable teaching contents in EAP as academic norms, academic awareness, academic literacy and so on. Therefore, it is shown that undergraduates in agricultural university in border provinces subjectively recognize the necessity and importance of EAP, despite their weak English foundation.

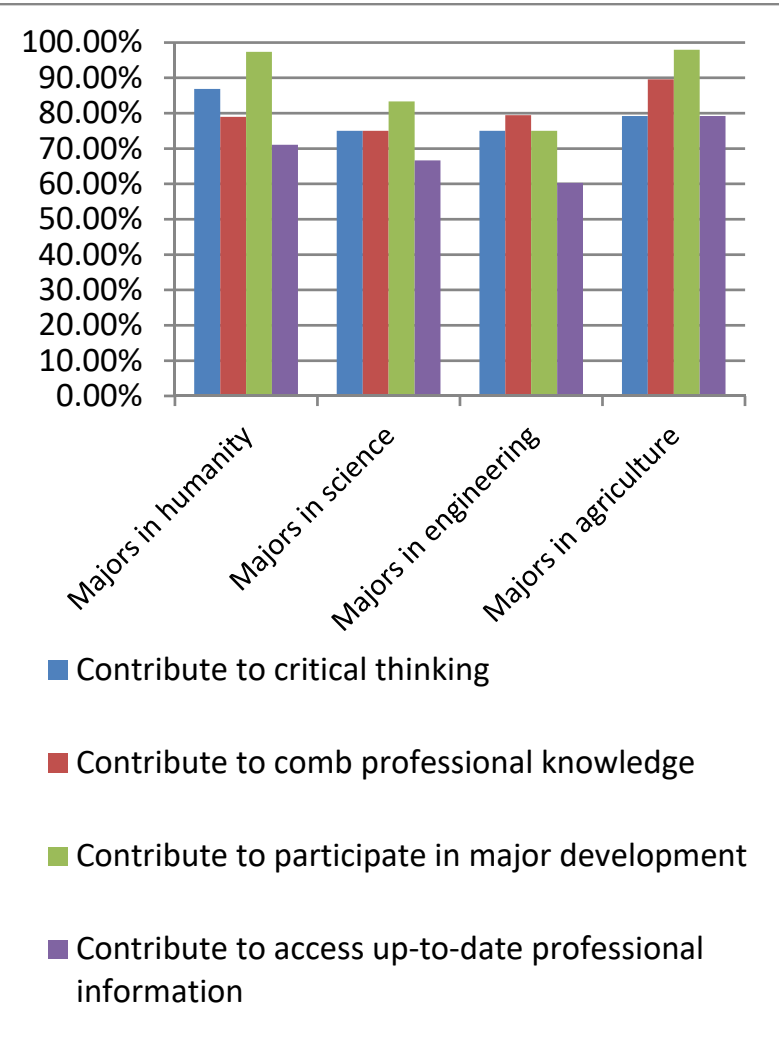

Figure 3 Undergraduates' views about writing academic papers

However, when making plan of writing papers, many undergraduates gave negative answers (see Figure 4), which shows the lack of confidence of writing paper and weak academic awareness. It is noteworthy that, despite the low passing rate of CET-4 (27\%), compared with other majors, more than $20 \%$ undergraduates in agricultural majors plan to challenge English papers, which indicates their need of EAP as well as comparatively high research ability and strong academic awareness. From the above analysis, we believe that during the overwhelming reform and innovation of neoAgriculture education, cultivation of international agricultural talents are of great significance and necessity.

\subsection{Dissatisfaction of the Present College English Course}

Most undergraduates are dissatisfied with the present college English course. To investigate undergraduates' view toward the present college English 


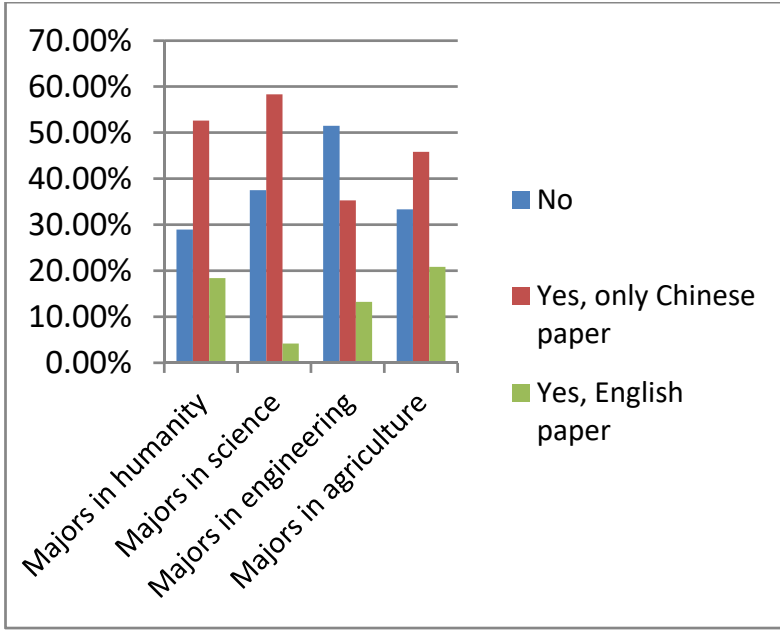

Figure 4 Undergraduates' plan about writing papers

course which is mainly about general English, the author designed the question: "Is your English improved after entering into university?" Respondents were required to choose "Yes, Not sure or No" to answer the question (see Figure 5) 68\% freshmen chose "not sure", partly because they were expecting more about college English at that time. $66 \%$ juniors gave the negative answer, which may result from their complicated and frustrated attitude towards English learning. According to the present college English course design, 4 semesters of college English in freshman and sophomore years impressed juniors negatively, and their poor grade in CET-4 (failure rate: $61 \%$ ) frustrates them a lot when applying for postgraduate university.

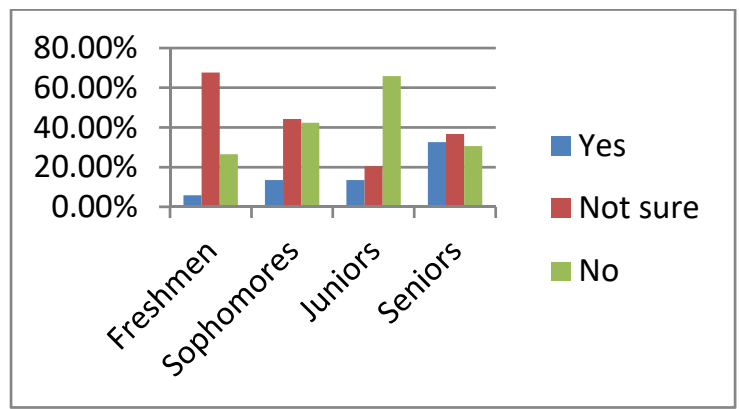

Figure 5 Undergraduates' view toward whether their English level is improved in university.

It is noteworthy that, compared with only $6 \%$ juniors, $33 \%$ seniors think that their English is improved, partly due to they just attended Postgraduate Entrance Exam when answering the questionnaire. The English test of Postgraduate Entrance Exam aims to select excellent and promising research talents, so the English score is critical to apply for top postgraduate universities. The English test syllabus of Postgraduate Entrance Exam test (2020) states explicitly that applicants are supposed to understand professional literatures, which requires flexible reading skills and fundamental academic literacy [10]. In preparing for the English test of Postgraduate Entrance Exam, senior's improved English level further indicates that, compared with general English, EAP caters for the need of undergraduates. Therefore, we have to recognize the overwhelming trend of college English reform in agricultural universities in border provinces; on the one hand, EAP is the desperate need of students, on the other hand, the cultivation of international talent with excellent academic literacy during the development of neo-agriculture education also calls for the reform.

\subsection{Weak Awareness of Academic Norms}

In 2012, Cai Jigang conducted a survey for 4 top universities in Shanghai, finding that $81 \%$ undergraduates agree that "as long as the source is given, it is acceptable to cite the original text without paraphrase" [11]. However, in the present survey for the agricultural university in the border province, only $43 \%$ undergraduates hold the similar opinion (see Table 1), which reflects comparatively strong awareness of academic norms, partly due to the attention and reflection of academic misconducts both in home and aboard reported in recent years. Though the proportion, reflecting weak awareness of academic norms, dropped largely in the past 9 years, the alarming proportion in the present survey, $43 \%$, still deserves our attention. Weak awareness of academic norms is still a critical problem to be solved in neo-agricultural education. As one of the development direction of neo-agricultural education, college English reform may facilitate to improve the situation since academic norms is a necessary and important part in EAP.

Table 1. The question to examine Undergraduates' academic norm

\begin{tabular}{|c|c|c|}
\hline Question & Agree & Disagree \\
\hline $\begin{array}{l}\text { As long as the source } \\
\text { is given, it is acceptable to } \\
\text { cite the original text } \\
\text { without paraphrase. }\end{array}$ & $43 \%$ & $57 \%$ \\
\hline
\end{tabular}

\section{SUGGESTIONS ABOUT EAP TEACHING}

From the above analysis, such subjective factors as improper learning aim, high expectation of college English, weak awareness of academic norm, combining with realistic factor---the low English level, compose the huge barrier to college English reform. Objectively, it may be harder to give EAP teaching in agricultural universities in the border provinces than in top universities. From which aspect can we improve our EAP teaching? The author lists the following suggestions especially for agricultural university. 


\subsection{Waken Undergraduates' Awareness to Write Professional Papers.}

It is unreasonable that dissertation is the first formal professional paper for most undergraduates. This survey shows that most undergraduates recognize the importance and significance of writing papers which contributes to comb and summarize the professional knowledge and cultivate the critical thinking. Why should not design the course of paper writing at the elementary and middle stage of major learning? A large amount of undergraduates no longer learn English after getting a satisfying score of CET-4, because they view English as an exam instead of a tool to obtain professional knowledge. Consequently, their major horizon is limited to the Chinese textbooks and lectures professors gave. So both the English teachers and teachers of professional courses in agricultural universities should broaden the undergraduate's horizon with EGAP and ESAP, and open a fresh door for undergraduates to view their major from a promising, dynamic and international perspective. Only in this way can students transfer their passive learning into active learning of English.

\subsection{Build EGAP Course according to 4 Major Categories}

EGAP course is encouraged to be integrated into 4 major categories in agricultural universities. The category should not be as specific as ESAP which is designed in terms of each major or even subject. Take Yunnan Agricultural University as an example, college English reform is carried out according to 4 major categories: humanity, science, engineering and agriculture. Since the ultimate teaching objective of EAP is to facilitate students to understand professional literature, building EGAP course under 4 major categories will be helpful to organize teaching activities. With the different indexes, experiment methods and reference styles, EGAP course under different major categories will help both teachers and students to explore the features of one category, familiarize the searching channels and finally write papers of professional literature about one major category.

\subsection{Develop EAP MOOCs for Agricultural Purpose}

EAP MOOC about practical literature reading skills and academic focuses will bridge the large teaching level gap between top universities and agricultural universities in border provinces. EAP teachers in agricultural universities are encouraged to develop EAP MOOCs for agricultural purpose, taking the above 4 problems into consideration. On the one hand, short and succinct MOOCs, breaking the time and space limitation, are friendly to agricultural students whose English is poor; on the other hand, students can get fully prepared for the coming class by watching MOOCS in advance, bringing puzzles to class, finally creating an open and efficient flipped classroom.

\subsection{Establish Extended Class of EAP}

Yunnan Agricultural University has successfully held postgraduate academic English competition (similar to an international academic seminar) twice, which requires postgraduate to report in English the significant findings about their major after grasping all academic reading skills, article components and other academic focuses. To prepare the presentation, postgraduate are encouraged to search and read an English article in a group; during the preparation, academic language focuses in EAP course will help them understand the English article. The competition is spoken highly both by teachers and students, who can sense the achievement of academic communication. The author thinks that this competition also extends the EAP course well for undergraduates in agricultural universities.

Writing guidance center is a popular institution in universities abroad, which helps students who have language difficulties in writing paper, especially when they have achieved outstanding research outcomes. EAP Writing guidance center is an ideal way to extend EAP class, even in the following years after students have finished the EAP courses.

\section{CONCLUSION}

In this survey, the author find that there are large differences of the perception of EAP between undergraduates in China's top universities and in agricultural universities in border provinces, mainly about the present English level, the learning aims of college English, academic awareness and the academic norms. The survey indicates that most students recognize the significance of writing papers and expect highly about EAP courses, even though their English level is not satisfying right now. EAP can not only enhance students' general English, but also can improve students' English academic literacy, which is indispensable to cultivate creative and international talents in the development of neo-agriculture education. Despite the huge difficulties, college English reform is an overwhelming trend, and EAP should be an ideal orientation.

\section{PROJECT FUND}

This paper is one of the achievements of research project of the Education Department of Yunnan province: "Research on the Phenomena of Semiology of Professional Title in Yunnan Universities" (Project number: 2018JS276). 


\section{REFERENCES}

[1] The National Foreign languages Teaching Advisory Board under the Ministry of Education, Teaching Guide of College English. Higher Education Press, Beijing, 2020.

[2] The Ministry of Education, (2019) "Beijing Guide" issue: construction of neo-agriculture education launches "One Hundred Universities with One Thousand Projects", 2019.

http://www.moe.gov.cn/s78/A08/moe 745/201912 tt20191219_412637.html

[3] Jordan, R.R., English for academic purposes: A guide and Resource Book for Teachers. Cambridge University Press, London, $1997 . \quad$ DOI: 10.1017/CBO9780511733062.023

[4] Ma Wulin, Research on course content of successive courses of college English | --academic English. Foreign Language Research, 2011, PP.15-21. DOI : 10.3969/j.issn.10057242.2011.05.004

[5] Cai Jigang, Course modals design of college ESP based on need analysis. Foreign Language Teaching, 2012, PP. 47-50. DOI : CNKI: SUN: TEAC. 0.2012-03-010

[6] Sinha, A.C. \& L.C. Sadorra, A Primer on ESP: For Teachers of English. De Salle University Press. Philippines, 1991.

[7] Liu Gequn, Statistics, analysis and implication of SCI papers published by undergraduates. Research on Education Theory, 2013, PP.189-191.

[8] Cai Jigang, A revisit to the EAP needs analysis of university students of non-English major and specialists under the background of "Double FirstClass" initiative. Foreign Language Education in China, 2019, PP. 2:47-54.

[9] Cai Jigang, Analysis of Students and Faculty's Needs for ESP in the Context of the Internationalization of Higher Education. Computer-assisted Foreign Language Education, 2013, PP. 153:3-9. DOI: 10.3969/j.issn.10015795.2013.05.001

[10] The Ministry of Education, English test Syllabus of national postgraduate entrance exam. Higher Education Press, Beijing, 2019.

[11] Cai Jigang, Academic English: Needs analysis and teaching methods. Foreign Language Learning Theory and Practice, 2012. 